\title{
PENERAPAN EKSTRAKSI CIRI ORDE SATU UNTUK KLASIFIKASI TEKSTUR MOTIF BATIK PESISIR DENGAN ALGORITMA BACKPROPAGASI
}

\author{
Novita Kurnia Ningrum \\ Program Studi Teknik Informatika, Fakultas Ilmu Komputer \\ Universitas Dian Nuswantoro Semarang \\ Email: novita.kn@dsn.dinus.ac.id \\ Defri Kurniawan \\ Program Studi Teknik Informatika, Fakultas Ilmu Komputer \\ Universitas Dian Nuswantoro Semarang \\ Email: defri.kurniawan@dsn.dinus.ac.id \\ Novi Hendiyanto \\ Program Studi Teknik Informatika, Fakultas Ilmu Komputer \\ Universitas Dian Nuswantoro Semarang \\ Email: novi.hendriyanto@gmail.com
}

\begin{abstract}
ABSTRAK
Wilayah pesisir pantai pulau Jawa yang meliputi kota Brebes, Cirebon, Pekalongan, Lasem dan Madura memiliki pola motif batik yang beragam. Berdasarkan ragamnya, motif batik pesisir dibedakan menjadi batik geometri dan nongeometri. Pada awal pengolahan citra batik ini dilakukan cropping secara manual pada citra batik pesisir dengan merubah ukuran piksel menjadi 60 x 60 piksel. Dilanjutkan greyscaling pada citra cropping. Klasifikasi motif batik pesisir menggunakan algoritma bakpropagation dengan menentukan nilai learning rate dan momentum pada saat training data. Data inputan yang digunakan berupa ciri statistik orde satu. Ciri statistik yang digunakan antara lain mean, kurtosis, skewness dan enteropy. Hasil uji coba menunjukkan learning rate terbaik diperoleh pada 0,5 dan momentum 1,0 pada motif batik geometri. Sedangkan pada motif batik non geometri learning rate terbaik diperoleh pada 0,5 dan momentum 1,0 .
\end{abstract}

Keywords: learning rate, momentum, backprogation, motif batik pesisir.

\section{ABSTRACT}

The coastal areas of Java island covering the cities of Brebes, Cirebon, Pekalongan, Lasem and Madura have various patterns of batik motifs. Based on the variety, coastal batik motifs are divided into batik geometry and nongeometri. At the beginning of this batik image processing done cropping manually on the image of coastal batik by changing the size of pixels to $60 x 60$ pixels. Continued greyscaling on the cropping image. Classification of coastal batik motif using bakpropagation algorithm by determining the value of learning rate and momentum during training data. Input data used in the form of first order statistics. Statistical features that used in this reasech is mean, kurtosis, skewness and enteropy. Result of the reasech is the best learning rate is 0.5 and the momentum 1.0 on the geometry of batik motif. And non-geometric motif the best learning rate 0,5 and momentum 1.0.

Keywords: learning rate, momentum, backprogation, motif batik pesisir.

\section{PENDAHULUAN}

Berdasarkan bidang seni rupa, batik termasuk dalam karya lukis dua dimensi dimana kain yang menjadi media lukisnya. UNESCO telah mengakui batik sebagai karya seni asli warisan budaya masyarakat Indonesia pada tahun 2009 [1]. Di Pulau Jawa batik berkembang pesat di wilayah pesisir utara Pulau Jawa atau biasa disebut batik pesisir dan lingkungan kraton Yogyakarta dan Solo atau biasa disebut batik pedalaman. Batik pesisir berkembang pesat di kota sepanjang pesisr utara pulau Jawa, meliputi Brebes, Cirebon, Pekalongan, Lasem dan Madura. Menurut Nian S. Djoemana, secara garis besar ragam hias batik dibedakan menjadi 2, yaitu ragam hias geometri dan non geometri [2]. 
Motif batik memiliki empat elemen dasar di dalamnya, yaitu garis, tekstur, warna dan bidang [1]. Dengan pengolahan citra motif pada batik dapat dianalisa untuk kemudian diklasifikasikan berdasarkan empat elemen yang dimilikinya. Dengan adanya klasifikasi akan membantu identifikasi karakter pada objek citra yang tersimpan dalam database, sehingga dapat meminimalkan kesalahan memasukkan objek pada kelompok yang berbeda [3].

Motif batik dapat diklasifikasikan berdasarkan karakteristik fiturnya dengan mencari kesamaan ciri dari citra tersebut. Ciri fitur diperoleh dengan ekstraksi fitur, dimana fitur citra dapat berupa bentuk, tekstur dan warna [4]. Penelitian terkait dengan ciri statistik dilakukan oleh Dyah Norma untuk mengklasifikasi serat pada kayu berdasarkan tekstur serat miringnya. Parameter yang digunakan pada klasifikasi adalah jarak euclidean untuk menghitung tingkat akurasi dan waktu komputasi [5]. Penelitian tersebut menunjukkan bahwa ekstraksi fitur orde satu pada ciri entrophy menghasilkan Backpropagation adalah salah satu metode klasifikasi berdasarkan jaringan saraf tiruan (artificial network). Penelitian yang terkait dengan backpropagatioan adalah penelian dari Anita Kasim dan Agus Harjoko. Tujuan dari penelitian tersebut adalah untuk mengklasifikasikan motif batik geometri dan nongeometri. Hasil penelitian menunjukkan bahwa bacpropagation dapat mengklasifikasi citra motif batik berdasarkan motif geometri dan nongeometri. Tingkat akurasi mencapai $100 \%$ pada motif geometri dan $85,71 \%$ pada motif nongeometri dengan jumlah neuron sebanyak 20 neuron [6].

Dengan adanya sitem komputasi digital diharapkan dapat membantu dalam mengelola data motif batik secara digital dan dapat mengenali motif batif batik dengan mudah dengan menggunkan sistem tersebut.

\section{METODOLOGI PENELITIAN}

Pada pengolahan citra, tahapan ekstraksi fitur diperlukan untuk intepretasi citra sehingga memudahkan analisa citra pada proses klasifikasi. Ekstraksi ciri berdasarkan analisi tekstur pada umumnya membutuhkan ekstrkasi ciri pada tahap awal. Salah satu ekstrkasi ciri dapat dilakukan dengan ekstraksi ciri orde satu. Setiap pola memiliki ciri spesifik yang dapat diklasifikasikan ke dalam kelompok pola geometri dan pola nongeometri. Selanjutnya menggunakan backpropagation untuk mengklasifikasi motif batik berdasarkan pola geometrinya.

Algoritma backpropagation termasuk dalam algortima pembelajaran jaringan saraf tiruan atau neural netwoks yang dipopulerkan oleh oleh Rumehalt dan Mc Celland [7]. Sistem kerja backpropagation mengadopsi sistm kerja saraf pada manusia. Metode pembelajaran (learning) yang diadopsi backpropagation termasuk dalam supervised learning. Nilai yang diberikan pada input neurons merupakan pengetahuan yang dijadikan acuan untuk dipetakan ke dalam kelompok yang diinginkan yang sudah ditentukan di output neurons.

Learning process akan terus dilakukan selama kondisi yang diinginkan belum terpenuhi, hingga mencapai nilai error yang paling kecil. Oleh karenanya backpropagation sesuai untuk mengklasifikasi pola yang kompleks [8]. Klasifikasi batik dengan backpropagation berhasil memberikan nilai akurasi $100 \%$ untuk mengklasifikasi motif geometri dan 91,9\% untuk motif batik non geometri [6].

Tahapan pada penelitian ini meliputi akuisisi citra, pra pengolahan citra, ekstraksi fitur dengan metode ekstraksi ciri orde satu dan selanjutnya klasifikasi fitur dengan melakukan data training dan data testing dengan jaringan saraf tiruan algoritma backpropagation.

\subsection{Akuisisi Citra}

Pengumpulan data citra digital motif batik pesisir dan disimpan dalam format file extention jpeg.

\subsection{Pra Pengolahan}

Dilakukan cropping untuk menyamakan ukuran citra dengan resolusi 8 x 8 pixel. Kemudian greyscalling dengan merubah citra $R G B$ ke bentuk greyscale.

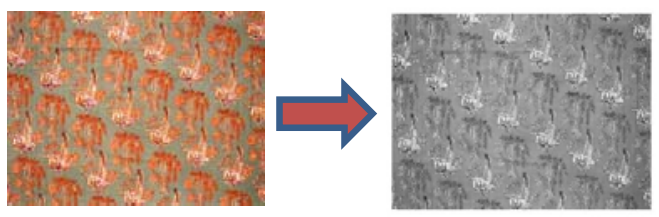

Gambar 6. Grayscaling Citra Motif Batik 


\subsection{Citra Ekstraksi Fitur}

Pada penelitian ini menggunakan ciri statistik ordo satu yang merupakan metode pengambilan ciri yang didasarkan pada karakteristik histograam citra dengan mengabaikan hubungaan antar piksel tetangga. Analisa tekstur orde satu lebih baik dalam mempresentasikan tekstur citra dalam parameterparameter terukur, seperti mean, skewness, kurtosis, dan entropy. Nilai ciri orde satu tersebut kemudian menjadi nilai inputan pada proses klasifikasi. Secara matematis perhitungan lima nilai ciri tersebut dijabarkan sebagai berikut.
a) $\operatorname{Mean}(\mu)$ probabilitas nilai histogram yang muncul pada citra.
b) Skewness $\left(\alpha_{3}\right)$
Merupakan tingkat kematangan relatif kurva histogram citra
c) Kurtosis $\left(\boldsymbol{\alpha}_{4}\right)$
Merupakan tingkat keruncingan relatif kurva histogram citra
d) Entropy (H)
Merupakan ukuran ketidakteraturan bentuk dari citra

Merupakan ukuran dispersi citra, dimana $f_{n}$ merupakan intensitas keabuan dan $p\left(f_{n}\right)$ adalah

\subsection{Klasifikasi}

Backpropagation mengadopsi algoritma pembelajaran supervised learning dimana proses pembelajaran dilakukan pada saat data training. Data input pada input neurons dijadikan sebagai data training yang akan dilanjutkan ke output neurons sebagai data output. Setiap jaringan diberi bobot, jika nilai output belum sesuai dengan nilai yang diharapkan maka akan terjadi perbaikan bobot dan dipropagasi balik menyebar ke jaringan neuron sebelumnya. Iterasi terjadi hingga mencapai nilai error yang paling rendah. Berikut ini langkah kerja backpropagation:

a) Tahap 0: Inisiasi penimbang untuk pemberian nilai bobot $(w)$;

b) Tahap 1: mengulang tahap 2 sampai 9 hingga terpenuhi kondisi iterasi yang diinginkan;

c) Tahap 2: mengulang langkah 3 sampai 8 untuk tiap pasangan data training;

\subsubsection{Feedforward}

a) Tahap 3: setiap unit masukan $\left(\mathrm{X}_{\mathrm{i}, \mathrm{i}}=1,2, \ldots, \mathrm{n}\right)$ pada input neurons mendapapat sinyal dan diteruskan ke unit-unit berikutnya - pada hidden layer neurons;

b) Tahap 4: setiap unit pada hidden layer neurons dikalikan dengan bobot dan dijumlahkan faktor penimbang kemudian ditambahkan dengan nilai biasnya;

$$
Z_{-} \in n j=V_{0 j}+\sum_{i=1}^{n}\left(X_{t} V_{b j}\right)
$$

Membangkitkan aktifasi dengan fuungsi sigmoid:

$$
f=\frac{1}{1+\max (-f(x))}
$$

jika $Z_{j}=f\left(z_{-} i n_{j}\right)$ maka,

$$
z J=\frac{1}{1+e x p}(-2 \ln d)
$$

Selanjutnya sinyal dikirim ke unit output (output neurons) ;

c) Tahap 5: setiap unit output $\left(Y_{k}, \mathrm{k}=1,2, \ldots, \mathrm{m}\right)$ dikalikan lagi dengan faktor penimbang dan dijumlahkan

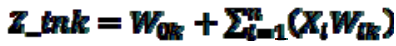

Kembali menghltung fungsi aktifasi

$$
y_{k}=f\left(y_{-} i n_{k}\right)
$$




\subsubsection{Backpropagasi Dan Perbaikan Nilai Error}

a) Tahap 6: Setiap unit output $\left(Y_{k}, \mathrm{k}=1,2, \ldots, \mathrm{m}\right)$ menerima pola target sesuai nilai masukan pada waktu data training dan menghitung nilai error

$$
\delta_{k}=\left(t_{k}-y_{k}\right) f^{\prime}\left(y_{t n-k}\right)
$$

Karena menggunakan fungsi aktifasi sigmoid, maka:

$$
\begin{aligned}
& f^{\prime}\left(y_{t n_{-} k}\right)=f\left(y_{t n, k}\right)\left(1-f^{\prime}\left(y_{t n, k}\right)\right. \\
& y_{k}=\left(1-y_{k}\right)
\end{aligned}
$$

menghitung faktor penimbang untuk nilai $W_{k j}$

$$
\Delta W_{k j}=a \cdot d, z j
$$

menghitung perbaikan koreksi,

$$
\Delta W_{0 k}=\alpha \cdot d_{k}
$$

Dan menggunakan nilai $\delta_{k}$ pada semua layer sebelumnya

b) Tahap 7: setiap nilai penimbang yang menghubungkan unit output dan unit hidden layer $\left(\mathrm{Z}_{j}\right.$, $j=1, . . p$ ) dikalikan delta dan dijumlahkan sebagai masukan pada unit layer berikutnya,

$$
\delta_{t n, j}=\sum_{t=1}^{m}\left(\delta_{k} W_{j k}\right)
$$

Kemudian dikalikan dengan turunan fungsi aktifasi untuk menentukan nilai error,

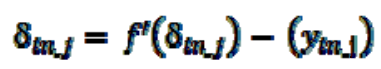

Menghitung perbaikan penimbang untuk memperbaiki $V_{t}$

$$
\Delta V_{t j}=\alpha \cdot c_{i} \cdot X l
$$

Menghitung perbaikan bias untuk memperbaiki $V_{o j}$

$$
\Delta V_{0 j}=a \cdot d_{1}
$$

\subsubsection{Memperbaiki Penimbang Dan Bias}

a) Perbaikan bias dan penimbang $(\mathrm{j}=0 . ., \mathrm{p})$ pada setiap unit output $\left(\mathrm{Y}_{\mathrm{k}, \mathrm{k}=1, . ., \mathrm{m})}\right.$

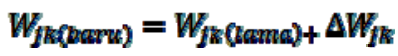

b) Memperbaiki bias dan penimbang $(\mathrm{j}=0, \ldots, \mathrm{n})$ pada unit hiden layer $(\mathrm{Zj}, \mathrm{j}=1, \ldots, \mathrm{p})$

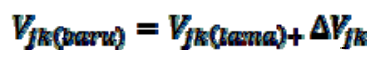

\section{HASIL DAN PEMBAHASAN}

Citra yang diolah sebanyak 100 citra motif batik pesisir, terdiri dari 45 citra geometri dan 55 citra non geometri. Pembentukan GLCM menghasilkan 5 ciri statistik yaitu means, skewness, kurtosis, entrophy. Adapun nilai yang dihasilkan sebagai berikut: 
Tabel 1. Hasil pembentukan nilai GLCM pada motif batik batik geometri

\begin{tabular}{crrrr}
\hline Citra & \multicolumn{1}{c}{ Mean } & \multicolumn{1}{c}{ kurtosis } & skewness & entropy \\
\hline imgeo1 & 873.375 & 10.1238 & 2.3325 & 1.2623 \\
imgeo2 & 938.4375 & 7.4431 & 1.793 & 2.1558 \\
imgeo3 & 821.2734 & 17.8547 & 3.858 & 1.3951 \\
imgeo4 & 905.25 & 2.7418 & 0.86953 & 1.2866 \\
imgeo5 & 895.7813 & 6.5037 & 2.1608 & 1.733 \\
imgeo6 & 930.0586 & 3.4862 & 1.3196 & 2.1984 \\
imgeo7 & 896.543 & 2.6609 & 1.1706 & 2.1069 \\
imgeo8 & 959.4609 & 134.9656 & 10.625 & 1.0532 \\
\hline
\end{tabular}

Tabel 2. Hasil pembentukan nilai GLCM pada motif batik batik non geometri

\begin{tabular}{crrrr}
\hline Citra & \multicolumn{1}{c}{ Mean } & Kurtosis & skewness & Entropy \\
\hline imgngeo1 & 914.9766 & 15.2619 & 3.5511 & 2.0110 \\
imgngeo2 & 992.7109 & 18.7283 & 4.0037 & 0.4899 \\
imgngeo3 & 986.9023 & 13.2245 & 3.1324 & 1.2357 \\
imgngeo4 & 964.2188 & 14.9091 & 3.0834 & 1.7428 \\
imgngeo5 & 1395.2695 & 6.2113 & 2.1252 & 0.7889 \\
imgngeo5 & 760.0781 & 10.1538 & 2.8000 & 1.2311 \\
imgngeo7 & 892.6875 & 84.1422 & 8.3966 & 2.7736 \\
imgngeo8 & 1583.2266 & 3.9668 & 1.4758 & 2.2712 \\
\hline
\end{tabular}

Empat nilai ciri seperti yang ditampilkan pada Tabel 1 dan Tabel 2 menjadi nilai masukan pada klasifikasi. Fase training mengggunakan $70 \%$ data training yang terdiri dari dan fase testing menggunakan $30 \%$ data testing.

Algoritma backpropagation menggunakan konsep learning/training dengan tujuan agar input yang diinisialisasi pada input layer menghasilkan output yang sesuai atau yang diinginkan. Oleh karena itu dibutuhkan nilai lerning rate yang mana nilai learning rate berkisar antara $0,1-1,0$. Selain itu dibuttuhkan adanya fungsi aktifasi,untuk menentukan nilai output suatu neuron sesuai dengan proses yang dilakukan terhadap input. Dalam hal ini fungsi aktifasi yang digunakan olrh algoritma backpropagasi adalah binary sigmoid function yang memiliki range antara 0 hingga 1.

Tabel 3 dan Tabel 4 menunjukkan hubungan learning rate dan momentum dengan jumlah neurons untuk menghasilkan nilai net error minimum.

Tabel 3. Training data dengan learning rate 0,5 dan momentum 0,1 pada motif geometri

\begin{tabular}{ccccl}
\hline \multicolumn{5}{c}{ Motif Geometri } \\
\hline $\begin{array}{c}\text { Jumlah } \\
\text { neuron }\end{array}$ & $\begin{array}{l}\text { Learning } \\
\text { rate }\end{array}$ & Momentum & Iterasi & $\begin{array}{l}\text { Net } \\
\text { error }\end{array}$ \\
\hline 10 & 0.5 & 0.1 & 500 & 0.00998 \\
12 & 0.5 & 0.1 & 785 & 0.00997 \\
20 & 0.5 & 0.1 & 2170 & 0.33776 \\
22 & 0.5 & 0.1 & 2584 & 0.20865 \\
25 & 0.5 & 0.1 & 2898 & 0.12859 \\
\hline
\end{tabular}


Tabel 4. Training data dengan learning rate 1,0 dan momentum 0.1 pada motif geometri

\begin{tabular}{|c|c|c|c|c|}
\hline \multicolumn{5}{|c|}{ Motif Geometri } \\
\hline $\begin{array}{l}\text { Jumlah } \\
\text { neuron }\end{array}$ & $\begin{array}{l}\text { Learning } \\
\text { rate }\end{array}$ & Momentum & Iterasi & $\begin{array}{l}\text { Net } \\
\text { error }\end{array}$ \\
\hline 10 & 1.0 & 0.1 & 10233 & 0.14371 \\
\hline 12 & 1.0 & 0.1 & 22490 & 0.1278 \\
\hline 20 & 1.0 & 0.1 & 24652 & 0.33569 \\
\hline 22 & 1.0 & 0.1 & 16155 & 0.21068 \\
\hline 25 & 1.0 & 0.1 & 9325 & 0.19467 \\
\hline
\end{tabular}

Tabel 3 menunjukkan nilai net error paling kecil yaitu 0.00997 diperoleh pada saat nilai learning rate 0,5 dan momentum 0,1 dengan jumlah neuron sebanyak 12 . Sedangkan pada Table 4 nilai net error paling kecil yaitu 0,12 juga diperoleh pada jumlah neurons 12 dengan learning rate 1,0 dan momentum 0,1 .

Tabel 5. Training data dengan learning rate 1,0 dan momentum 0.1 pada motif non geometri

\begin{tabular}{ccccc}
\hline \multicolumn{5}{c}{ Motif Non Geometri } \\
\hline $\begin{array}{c}\text { Jumlah } \\
\text { neuron }\end{array}$ & $\begin{array}{c}\text { Learning } \\
\text { rate }\end{array}$ & Momentum & Iterasi & $\begin{array}{c}\text { Net } \\
\text { Error }\end{array}$ \\
\hline 12 & 1.0 & 0.1 & 49173 & 0.355252 \\
20 & 1.0 & 0.1 & 3411 & 0.188532 \\
22 & 1.0 & 0.1 & 3848 & 0.333699 \\
25 & 1.0 & 0.1 & 2182 & 0.340964 \\
30 & 1.0 & 0.1 & 55831 & 0.459814 \\
40 & 1.0 & 0.1 & 7056 & 0.181231 \\
50 & 1.0 & 0.1 & 2143 & 0.11519 \\
60 & 1.0 & 0.1 & 829 & 0.213 \\
\hline
\end{tabular}

Tabel 6. Training data dengan learning rate 1,0 dan momentum 0.1 pada motif non geometri

\begin{tabular}{ccccc}
\hline \multicolumn{5}{c}{ Motif Non Geometri } \\
\hline $\begin{array}{c}\text { Jumlah } \\
\text { Neuron }\end{array}$ & $\begin{array}{c}\text { Learning } \\
\text { rate }\end{array}$ & Momentum & Iterasi & \begin{tabular}{c} 
Error \\
\hline 12
\end{tabular} \\
0.5 & 0.1 & 2202 & 0.02247 \\
20 & 0.5 & 0.1 & 46741 & 0.016422 \\
22 & 0.5 & 0.1 & 2388 & 0.09887 \\
25 & 0.5 & 0.1 & 11644 & 0.44773 \\
30 & 0.5 & 0.1 & 2882 & 0.057436 \\
40 & 0.5 & 0.1 & 8048 & 0.079793 \\
50 & 0.5 & 0.1 & 5058 & 0.065296 \\
60 & 0.5 & 0.1 & 1199 & 0.348121 \\
\hline
\end{tabular}

Jumlah neurons yang digunakan dalam backpropagation mempengaruhi learning/training, jumlah neurons terlalu sedikit menghasilkan net error yang kurang akurat dan jumlah neurons terlalu banyak menyebabkan fase learning/training tidak stabil. Jumlah data yang digunakan juga mempengaruhi seberapa banyak neurons yang akan melakukan training.

Perbaikan nilai bobot dan bias terus dilakukan jika masih terdapat nilai error yang dihasilkan oleh keluaran. Jika tidak ada lagi perbaikan dan nilai bobot tidak lagi berubah (stabil) maka iterasi akan dihentikan. Grafik pada gambar 5 dan gambar 6 menunjukkan epoch (jumlah iterasi) yang dicapai pada training validation dan testing pada motif geometri dan non geometri. Epoch pada motif batik geometri menunjukkan hasil terbaik di titik 4 demikian pula untuk validasi. Sedangkan epoch untuk motif non geometri stabil pada titik 6 . 

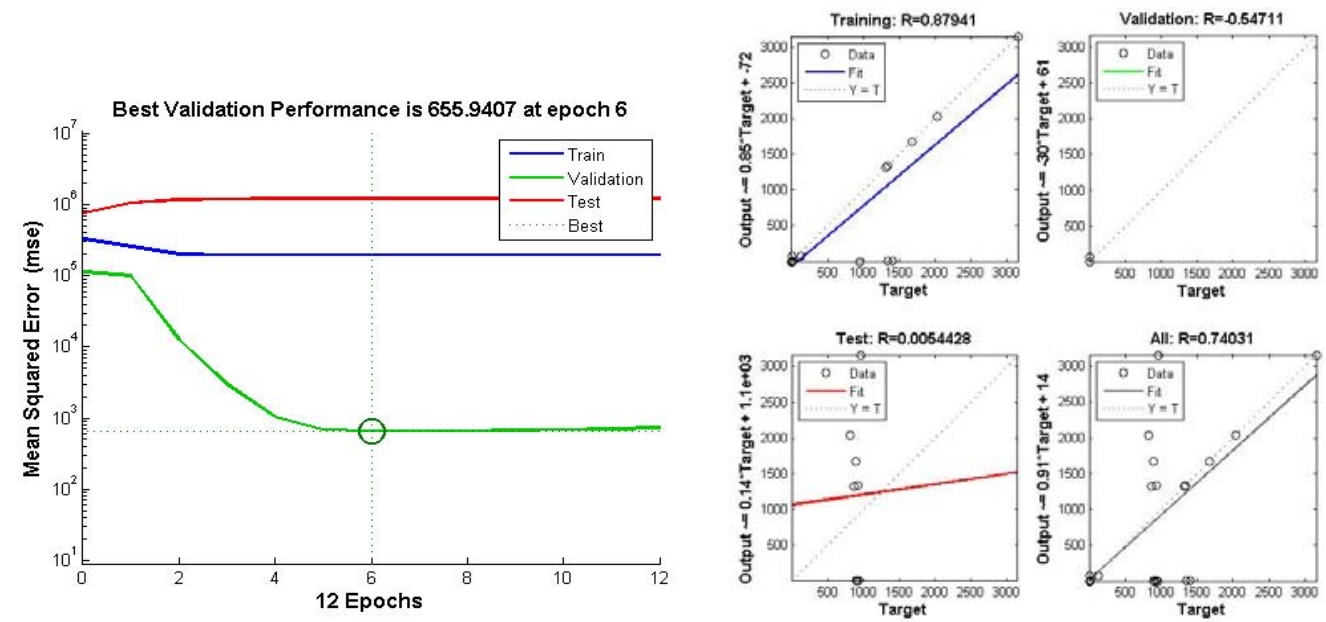

Gambar 5. Grafik Titk Epoch Terbaik Motif Geometri Dan Grafik Hasil Klasifikasi Motif Batik Geometri
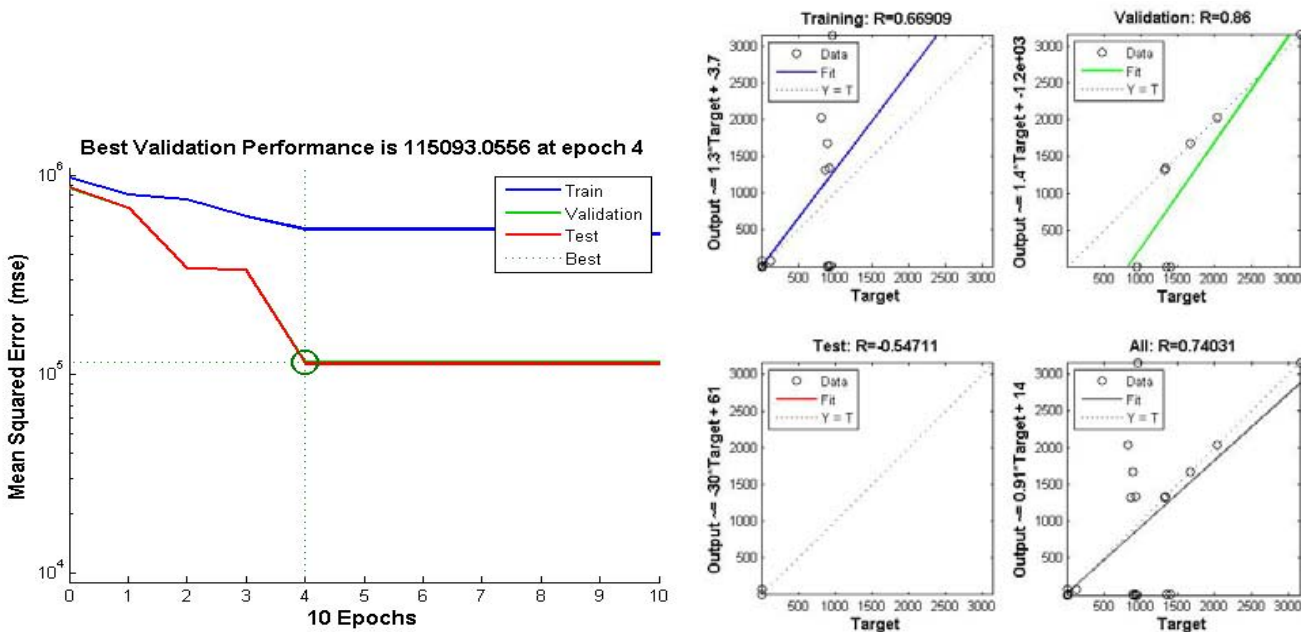

Gambar 6. Grafik Titik Epoch Terbaik Motif Non Geometri Dan Grafik Hasil Klasifikasi Motif Batik Non Geometri

\section{KESIMPULAN}

Berdasarkan uji coba di atas maka kesimpulan yang diperoleh adalah ekstraksi ciri orde satu dengan menghasilkan lima ciri statistik yaitu means, skewness, kurtosis dan enterophy. Dimana empat ciri terbut dapat dianalisa sebagai nilai input pada klasifikasi dengan algoritma backpropagation. Nilai learning rate mempengaruhi laju pada proses training. selain itu jumlah neurons yang digunakan menyesuaikan sengan jumlah data yang ditraining. Jumlah neurons yang terlalu banyak atau terlalu sedikit mengakibatkan iterasi semakin lama dan menjadi tidak stabil. Klasifikasi dengan algoritma backpropagation menghasilkan akurasi terbaik pada jumlah neurons 12 , learning rate 0,5 dan momentum 0,1 untuk motif batik geometri sedangkan motif batik non geometri akurasi terbaik pada jumlah neurons 20, learning rate 0,5 dan momentum 0,1. Nilai ciri statistk yang diperoleh pada penelitian ini masih terlalu generate sehingga membutuhkan proses yang lama untuk mendapatkan nilai akurasi terbaik pada klasifikasi.

\section{DAFTAR PUSTAKA}

[1] A. Arymurthy, Cbirs pada Aplikasi Warisan Budaya, 2011.

[2] N. S. Djumana, Batik, Yogyakarta: Departemen Perindustrian dan Perdagangan RI, 1997.

[3] V. S. Moertini and B. Sitohang, "Algorithms of Clustering and Classifying Batik Images Based on Color, Contrast and Motif," ITB J Eng Sci, vol. vol. 37 no. 2, p. pp 141-160, 2005. 
[4] H. Mauridhi and M. Arif, Konsep Pengolahan Citra Digital dan Ekstraksi Fitur, Edisi Pertama ed., JogJakarta: Pustaka Ilmu, 2010.

[5] D. N. Maharsi, . J. Halomoan and R. D. Atmaja, "Klasifikasi Serat Miring pada Kayu Menggunakan Ekstraksi Ciri Statistik Berdasarkan pada Pengolahan Citra," e-Procidings of engineering, vol. 2, no. 1, p. 2, 2015.

[6] A. A. Kasim and A. Harjoko, "Klasifikasi Citra Batik Menggunakan Jaringan Syaraf Tiruan berdasarkan Grey Level Co-Occurrance Matrices," Seminar Nasionatl Teknologi Informasi, p. Yogyakarta, 2014.

[7] D. G. Gonzalez and R. E. Fabio A., "A Semi-Automatic Method for Quantification and Classification of Erythrocytes Infected With Malaria Parasites in Microscopic Images," J. Of Biomedical Informatics, vol. 42, pp. 296-307, 2009.

[8] D. Puspitaningrum, Pengantar Jaringan Saraf Tiruan, Yogyakarta: Penerbit Andi, 2006.

[9] R. Albregtsen, Statistical Texture Measurer Computed from Gary Level Co-Occurrence Matrices, Oslo, 2008.

[10] Y. Rullist, B. Irawan and A. B. Osmond, "Aplikasi Identifikasi Motif Batik Menggunakan Ekstraksi Fitur Gary Level Co-Occurrence Matrix Berbasis Anroid".

[11] N. Setiohardjo and Harjoko A., "Analisis Tekstur untuk Klasifikasi Motif Kain (Studi Kasus Kain Tenun Nusa Tenggara Timur," IJCCS (Indonesian J Comput Cyber System), vol. 8, pp. 177-188, 2014.

[12] R. Hidayat, "Implementasi Penggabungan Metode Fitur Ciri Orde 1 dan Fitur Ciri Orde 2 Pada Citra Untuk Pengklasifikasian Jenis Batu Akik," Jurnal Ilmiah Komputer dan Informatika (KOMPUTA).

[13] Group Imaging \& Image Processing Research, "PRAKTIKUM PENGOLAHAN CITRA BIOMEDIKA, Modul 3 - Analisis Tekstur," ITB. 